\title{
Influence of Raw Materials Ratio on Properties of New Magnesium Phosphate Cement
}

\author{
Jin-Mei DONG ${ }^{1, a}$, Hong-Fa YU ${ }^{1,2,3, b^{*}}$, Xue-Ying XIAO ${ }^{1, c}$, Jing WEN ${ }^{1}$, Ying $\mathrm{LI}^{1}$, \\ Cheng-Gong $\mathrm{CHANG}^{1}$ and Wei-Xin $\mathrm{ZHENG}^{1}$
}

\author{
${ }^{1}$ Qinghai Institute of Salt Lakes, Chinese Academy of Sciences, No.18, ${ }^{\text {xining }}$ 810008, PR China; \\ ${ }^{2}$ Civil Engineering Institute, Qinghai University, Xining 810016, PR China; \\ ${ }^{3}$ Department of Civil Engineering, Nanjing University of Aeronautics and Astronautics, Nanjing \\ 210016, PR China \\ adongda839@163.com, ${ }^{b}$ yuhongfa@nuaa.edu.cn, ${ }^{c}$ xiaoxy@isl.ac.cn
}

Keywords: By-products of extracting lithium boron magnesium oxide (B-MgO), Magnesium phosphate cement (MPC), compression strength; phases and microstructure.

\begin{abstract}
Magnesium Phosphate Cement (MPC) was prepared by using the by-products of extracting lithium boron magnesium oxide (B-MgO ) as raw material. The influence of hydration hardening process was studied by testing setting time and compressive strength of different raw materials ratio of MPC. The phase composition and microstructure of hardening body morphology was analyzed by XRD and SEM. The result shows that there is a little impact of the distribution of raw materials ratio to the setting time, but the effect is remarkable to the compressive strength, phase content and microstructure of hardening body. By XRD and SEM observation, the best raw material proportioning of MPC has the highest generation of hydration products which from small petals of acicular crystals to rod and flat crystallization with a high degree of crystalline and compact structure and less defect.
\end{abstract}

\section{Introduction}

Magnesium phosphate cement (MPC) is composed of sintered magnesia, phosphate, and retarder; it is fast-setting, good plasticity and adhesiveness and exhibits early high strength [1 5]. Magnesium oxide used in MPC is obtained by calcining alkali magnesium carbonate $\left(\mathrm{Mg}(\mathrm{OH})_{2} \cdot 4 \mathrm{MgCO}_{3} \cdot 5 \mathrm{H}_{2} \mathrm{O}\right)$ or medical-grade $\mathrm{MgO}$ at $1400^{\circ} \mathrm{C}-1700^{\circ} \mathrm{C}[6 \sim 11]$. In this paper, we use the by-products of extracting lithium boron magnesium oxide (B-MgO) as raw material for the preparation of MPC. In salt lake brine extraction of lithium carbonate process, no matter adopt what kind of process, the extraction of 1 ton of lithium carbonate products, all can produce about 10 tons of by-product magnesium oxide, this magnesium oxide have low activity, product hydration reaction difficultly and contain a small amount of boron and boron and magnesium separation difficult, so usage is very limited. However, it is suitable for the preparation of MPC as raw material. In this material, boron as retarder can play a retarding effect [12], no need to add retarder additionally, simplify the process.

The mass ratio of magnesium oxide and potassium dihydrogen phosphate in MPC has important influence for physical mechanics property of MPC. Weil, etc.[13] have studied the performance of the MPC, considered the basic components of MgO compared with ammonium dihydrogen phosphate components should be excessive, excessive amounts of $\mathrm{MgO}$ as a skeleton of the system can improve its hardening strength, but this ratio must meet certain requirements. In this paper, the raw material ratio on the properties of new magnesium phosphate cement was studied. Physical and mechanical properties of MPC were researched by measuring its setting time, hydration heat release curve, compressive strength. Phase and microstructure were analyzed combined with XRD and SEM. 


\section{Experimental Studies}

\section{Raw Materials}

Magnesium oxide was the B-MgO byproduct after extracting $\mathrm{Li}_{2} \mathrm{CO}_{3}$ from salt lakes at Qinghai Citic Guoan Technology, China. The main chemical composition and physical phase composition see literature $[14,15]$, the $\mathrm{B}-\mathrm{MgO}$ need calcinations at $1000^{\circ} \mathrm{C}$ for $3 \mathrm{~h}$ to decompose $\mathrm{Mg}(\mathrm{OH})_{2}$ to MgO before preparing MPC.

Analytical grade potassium dihydrogen phosphate $\left(\mathrm{KH}_{2} \mathrm{PO}_{4}\right.$ or $\left.\mathrm{KDP}\right)$ was provided by the National Medicine Group Chemical Reagent Co., China. Before preparing the MPBC, it was dried at $60^{\circ} \mathrm{C} \pm 1^{\circ} \mathrm{C}$ for $24 \mathrm{~h}$ to remove free water.

\section{Experimental Methods}

\section{Setting Time}

The setting time of the cement pastes was determined using a modified Vicat needle according to ASTM standard C807-05. After the sample molding, try using needle contact surface of sample, let the slider free fall, try to pin down sample is less than $1 \mathrm{~mm}$, the time required was setting time.

\section{Compressive Strength}

The compressive strength of hardened MPC specimens was measured with a SANS-Microcomputer controlled electronic universal testing machine (CMT6104) with a compression speed of $5 \mathrm{~mm} / \mathrm{min}$. There samples were tested for each composition and time point.

\section{Crystal phase and Microstructure}

The crystal phase of samples cured for $3 \mathrm{~h}$ and 28 days was identified with an X'pert Pro X-ray diffractometer with $\mathrm{Cu} \mathrm{L} \alpha$ radiation. The sample was ground to particles of less than $35 \mu \mathrm{m}$. Scanning electron microscopic (SEM) imaging was performed on dried gilded specimens (JSM-5610LV).

\section{Results and Discussion}

\section{Setting Time and Adiabatic Temperature Curve of MPC}

The setting time of different mass ratio of $\mathrm{M} / \mathrm{K}$ are shown in Table 1 . Fixed liquid-solid ratio of $0.22: 1$, the $\mathrm{M} / \mathrm{K}$ has a certain influence on the setting time, but overall change is not big, all around 6 to $8 \mathrm{~min}$. With the increase of $\mathrm{M} / \mathrm{K}$, the setting time shortened. It shows that setting time is associated with the concentration of $\mathrm{Mg}^{2+}$ in the solution. The more $\mathrm{Mg}^{2+}$, the shorter setting time.

Table 1 The setting time of different mass ratio of $\mathrm{M} / \mathrm{K}$

\begin{tabular}{clllll}
\hline $\mathrm{M}: \mathrm{K}$ & $1: 1$ & $1.5: 1$ & $2: 1$ & $2.5: 1$ & $3: 1$ \\
\hline Setting time/min & 8 & 7 & 7 & 6 & 6 \\
\hline
\end{tabular}

\section{MPC Compressive Strength}

Compressive strength is an important index of bone repair material quality. The compression strength at different mass ratio of $\mathrm{M} / \mathrm{K}$ at 1 and 3 hours and 1, 3, 7, 14 and 28 days are shown in Figure 1. Different mass ratio of $\mathrm{M} / \mathrm{K}$ had a substantial effect on MPC compressive strength. Increasing the mass ratio of magnesium oxide initially increased MPC compressive strength, but this index then decreased, thus revealing an ideal mass ratio range. At the mass ratio of 1:1 2:1, maximum compressive strength at $1 \mathrm{~h}$ and $3 \mathrm{~h}$ reached 55.5 MPa and 87.2 MPa respectively; however, the 3-day and 28-day strength reached 92.1 MPa and 83.3 MPa, which was essentially the same as at 3-h. Further increase the mass ratio of magnesium oxide at 2.5:1 and 3:1 rapidly reduced the $1 \mathrm{~h}$ to $28 \mathrm{~d}$ compressive strength at each stage. 


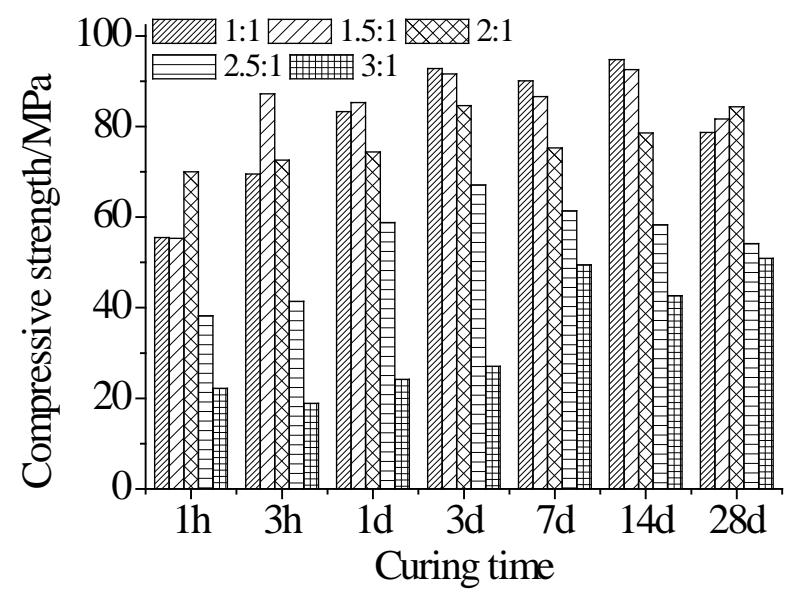

Figure 1 The influence of different M/K ratio on compressive strength of MPC

\section{MPC Phase Composition}

Figure 2 shows the effect of different mass ratio of M/K on MPC phase composition at $1 \mathrm{~h}$ (Fig. 2a) and $28 \mathrm{~d}$ (Fig. 2b). It shows that the main hydration products of MPC are $\mathrm{KMgPO}_{4} \cdot 6 \mathrm{H}_{2} \mathrm{O}(\mathrm{MKP})$, unreacted $\mathrm{MgO}$ and $\mathrm{Mg}_{3} \mathrm{~B}_{2} \mathrm{O}_{6}$. Different mass ratio of $\mathrm{M} / \mathrm{K}$ has little influence on characteristic peak of phase composition. The MKP main peak in different mass ratio of $\mathrm{M} / \mathrm{K}$ has been formed in the hardening at $1 \mathrm{~h}$. Compared with the main peak of MKP at 28-d, just sharp degree of the characteristic peak changed, the location of the characteristic peak and peak type are the same. It shows that the effect of different mass ratio of M/K on MPC phase composition is very small, and with the extension of hydration age, the degree of crystallization hydration products increased gradually.

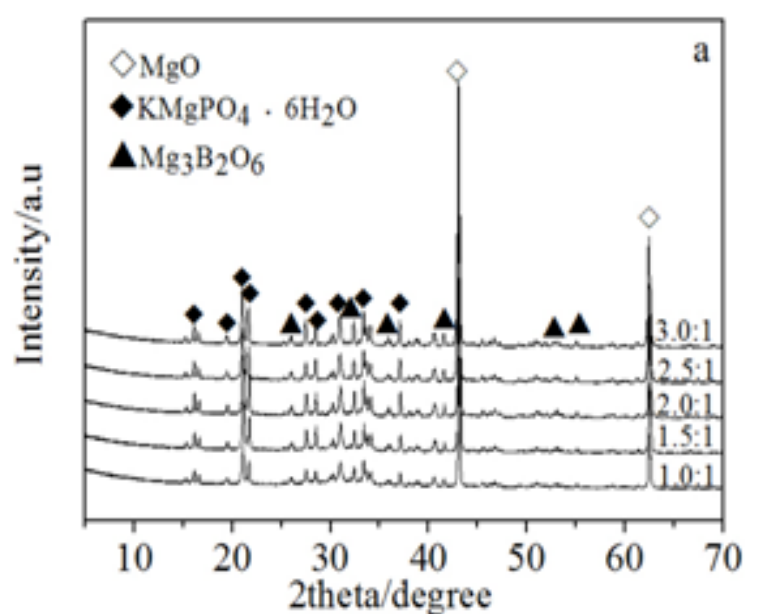

(a) $1 \mathrm{~h}$

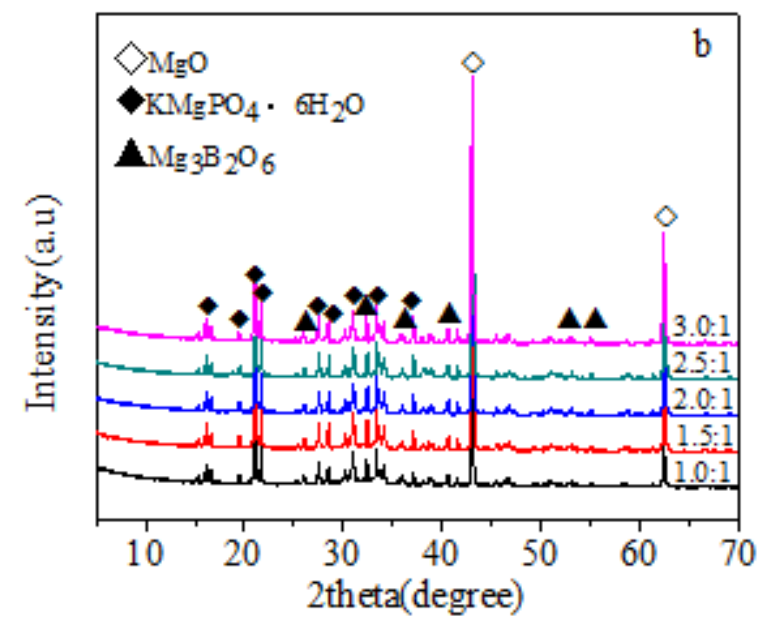

(b) $28 \mathrm{~d}$

Figure 2 The influence of different $\mathrm{M} / \mathrm{K}$ ratio on phase of MPC

\section{MPC Microstructure}

Figure 3 represents SEM micrographs of different mass ratio of M/K on MPC at 28-d. The figures show that different mass ratio of $\mathrm{M} / \mathrm{K}$ has great effect on the compactness of hardened body. When the mass ratio of $\mathrm{M} / \mathrm{K}$ is $1: 1$ (Fig. 3a), the morphology of hydration products are the thin sheet crystals stitching together, the structure of hardened body is compact within a small amount of micro cracks. When the mass ratio of $\mathrm{M} / \mathrm{K}$ increases to $1.5: 1,2: 1$ and 2.5:1 (Fig. 3b, 3c, 3d), the morphology of hydration products mainly as the long rod or plate shape crystals, the structure of hardened body is compact, too. Continue to increase the mass ratio of $\mathrm{M} / \mathrm{K}$ to $3: 1$, the hydration 
products have no obvious morphology, disorganized crystal loosely piled up together and the structure of the hardened body becomes loose.

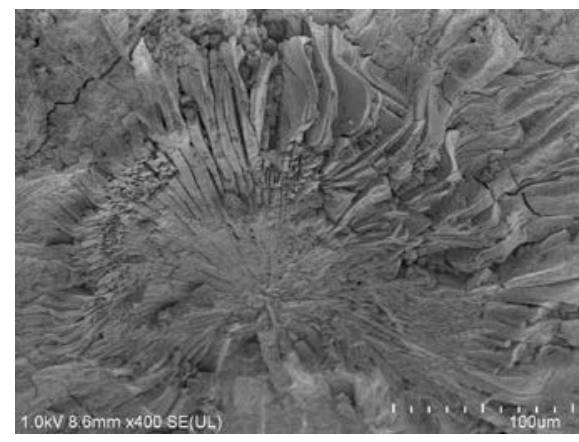

(a) $1: 1,28 \mathrm{~d}$

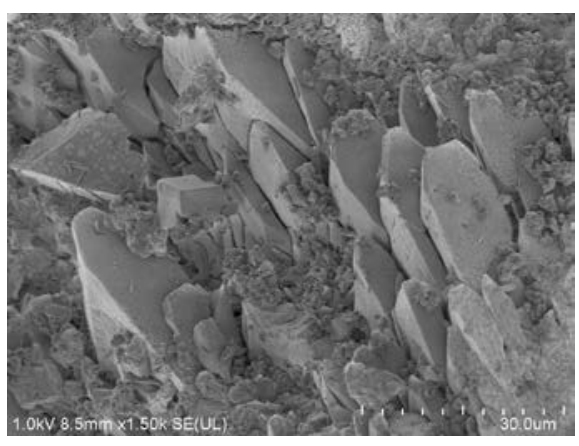

(b) $1.5: 1,28 \mathrm{~d}$

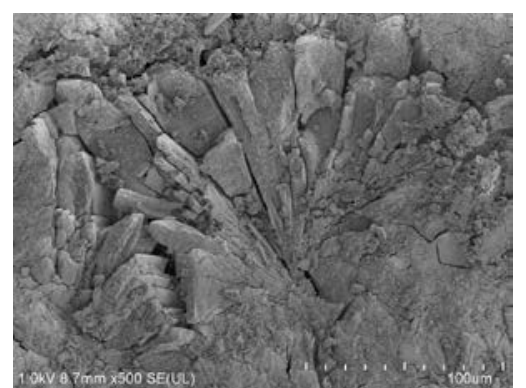

(c) $2: 1,28 \mathrm{~d}$

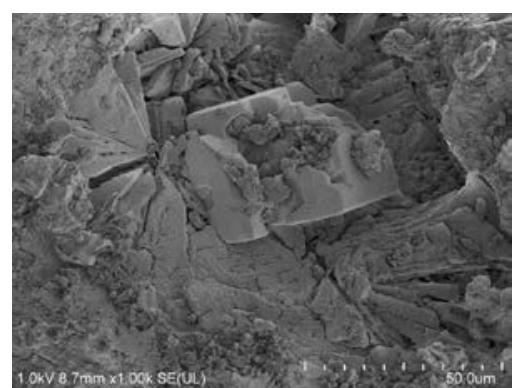

(e) 3:1, $28 \mathrm{~d}$

(d) $2.5: 1,28 \mathrm{~d}$

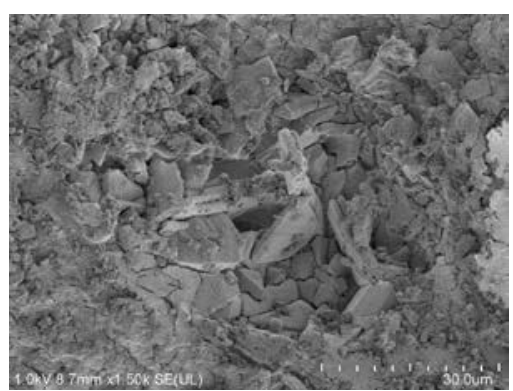

Fig. 3 The SEM photos on different ratio of MKPC at 28 day

\section{Conclusions}

(a) The mass ratio of $\mathrm{M} / \mathrm{K}$ among $1: 1$ to $3: 1$ has unconspicuous effect on the setting time and adiabatic temperature curve. The setting time is very short, all about 6 to $8 \mathrm{~min}$. The maximum heating temperature all among $60 \sim 75^{\circ} \mathrm{C}$; However, different mass ratio of $\mathrm{M} / \mathrm{K}$ had a substantial effect on MPC compressive strength, the optimal range of mass ratio of $\mathrm{M} / \mathrm{K}$ is from 1:1 to 2:1, the 1-hour and 28-day strength reached 55.5 MPa and 92.1 MPa respectively.

(b) Different mass ratio of $\mathrm{M} / \mathrm{K}$ has little influence on characteristic peak of phase composition. The main hydration product of MPC is $\mathrm{KMgPO}_{4} \cdot 6 \mathrm{H}_{2} \mathrm{O}$ (MKP); its content and microstructure can be easily modified by altering the mass ratio of $\mathrm{M} / \mathrm{K}$. The evolution process of the morphology of hydration product is by acicular crystal gradually grow into a bar, plate shape, triangle shape and finally growth into one of the thin crystal plate with $\mathrm{MgO}$ grains.

\section{Acknowledgement}

This research was financially supported by the National Natural Science Foundation of China (No.21276264) and the Qinghai Province Science and Technology Department(2013-G-208).

\section{References}

[1] Yang Q B,Wu X. Factors influencing properties of phosphate cement-based binder for rapid repair of concrete [J]. Cement and Concrete Research, 1999, 29 (3) : 389-396

[2] Yang Q B,Zhu B,Wu X. Characteristics and durability test of magnesium phosphate cement-based material for rapid repair of concrete [J]. Materials and Structures, 2000, 33(4) : 229-234

[3] Yang Q B,Zhang S,Wu X. Deicer-scaling resistance of phosphate cement-based binder for rapid 
repair of concrete[J].Cement and Concrete Research, 2002,32(1) :165-168

[4] Arun S Wagh, Seung Y Jeong. Chemically Bonded Phosphate Ceramics: I, A Dissolution Modle of Formation [J]. J. Am. Ceram. Soc., 2003, 86 (11):1838-1844

[5] Jiang Q Y, Zhang L M. Research of magnesium phosphate cement [J]. Journal of Wuhan University of Technology Materials Science, 2011, 23 (1):32-34(in chinese)

[6] Moseke C, Saratsis V, Gbureck U. Injectability and mechanical properties of magnesium phosphate cements [J]. J. Mater. Sci. Mater. Med., 2011, 22:2591-2598

[7] Sugama T and Kukacka L E, Magnesium polyphosphate cements derived from diammonium phosphate solutions, Cement Concr. Res., 1983,13: 407-416

[8] Mestres G, Ginebra MP. Novel magnesium phosphate cements with high early strength and antibacterial properties [J]. Acta Biomater., 2011,7:1853-1861

[9] Abdelrazig B.E.I., Sharp J.H., Jazairi B.E. The chemical composition of mortars made from magnesium-phosphate cement [J]. Cement Concrete Res,1988,(18):415-425

[10] Soude'e E, Pe'ra J. Mechanism of setting reaction in magnesium-phosphate cement[J]. Cement Concrete Res,2000(30):315-318

[11] Wu F, Wei J, Guo H, et al. Self-setting bioactive calcium-magnesium phosphate cement with high strength and degradability for bone regeneration [J]. Acta Biomater., 2008,4: 1873-1884

[12] Liu Qiuxia, Yan Yuhua. Effect of $\mathrm{B}_{2} \mathrm{O}_{3}$ on the Hydrolization of the phosphate bioglass [J].Journal of Wuhan University of Technology, 1998, 20 (3),34-36(in chinese)

[13] Weill P, et al. Magnesium phosphate cement system [P], U.S. Patent 4756762, 1986-12-07

[14] Yongshan Tan, HongfaYu, YingLi, etal. Magnesium potassium phosphate cement prepared by the byproduct of magnesium oxide after producing $\mathrm{Li}_{2} \mathrm{CO}_{3}$ from salt lakes [J]. Ceramics International, 2014,( 40): 13543-13551.

[15] Yongshan Tan, HongfaYu, YingLi, etal. Preparation of fly ash magnesium potassium phosphate cement used by the byproduct magnesium oxide from salt lakes and its properties[J].Journal of silicate, 2014, 42(11):1362 1368. (in chinese) 